\title{
A Health-Related Satisfaction with Life Scale Measure for Use with Cross-National Older Adults: A Validation Study
}

\author{
Sofia von Humboldt ${ }^{1} \&$ Isabel Leal $^{1}$ \\ ${ }^{1}$ William James Center for Research, ISPA — Instituto Universitário, Lisbon, Portugal \\ Correspondence: Sofia von Humboldt, William James Center for Research, ISPA-Instituto Universitário, \\ Lisbon, Portugal. Tel: 351-21-881-1700. E-mail: sofia.humboldt@gmail.com
}

Received: April 22, 2017

Accepted: May 8, 2017

Online Published: June 13, 2017

doi:10.5539/res.v9n3p21

URL: http://doi.org/10.5539/res.v9n3p21

\begin{abstract}
Objectives: Literature suggests some inconsistent results in the validity and reliability of the Satisfaction with Life Scale (SwLS) in older samples. The objective was to evaluate the psychometric properties of the SwLS in a cross-cultural sample of older adults.

Methods: This is a validation study to assess the psychometric properties of the SWLS in a sample of 1291 older adults 75 years of age or older, cross-culturally diverse and living in the community. A confirmatory factor analysis was performed. Item analysis and reliability, were also assessed.

Results: The systematic procedure used in the SwLS validation points to a good level of psychometric properties, such as reliability, construct, criterion validity, external validity and divergent criterion validity, suggesting that the SwL is assessing a construct different from the ones evaluated by PANAS and OtLQ.

Conclusion: The SwLS has demonstrated reliability, validity, and reproducibility for use in measuring health-related satisfaction with life among older adults in policy programs and interventions in community settings.
\end{abstract}

Keywords: cross-cultural, health aging, psycho geriatrics, quality of life, scales

\section{Introduction}

The world's older population is increasing at an incomparable pace. Currently, there are about 125 million people with 80 years or more and in 2050 the same age group is expected to total 434 million people (World Health Organization, 2015). Indeed, the proportion of older adults is growing exponentially worldwide (2.6\% per year) and considerably faster than the population as a whole, with major consequences, such as increasing costs associated with health care and social support, and challenges concerning aging well cross-culturally (World Health Organization, 2015). As longevity increases, the quality of that longer life becomes a central issue for older adults (World Health Organization, 2015).

Satisfaction with Life (SwL) corresponds to the cognitive facet of subjective well-being (Pavot \& Diener, 2004) and is defined as an overall cognitive and judgemental assessment of one's life including the current life (Diener Emmons, Larsen, \& Griffin, 1985). It was found to be related to gender, age, and socio-economic and educational level (Sposito, D’Elboux, Neri, \& Guariento, 2013). SwL is pertinent for aging well and successful aging (Brown, Bowling, \& Flynn, 2004) and may involve an assessment of life course goals and outcomes by the older individuals (Litwin, 2005). Some studies associated old age to a decrease in SwL, in part due to social, physical and psychological challenges in this stage of life, while others related old age to an increase in SwL (Angelini, Cavapozzi, Corazzini, \& Paccagnella, 2012; Gwozdz \& Sousa-Poza, 2010; von Humboldt, Leal, \& Pimenta, 2014). In fact, old age can be experienced differently by each individual; and likewise SwL results in late adulthood are not consistent (von Humboldt et al., 2014).

SwL has been related to positive health indicators, such as self-reported health, social support, and positive health behaviours (Koivumaa-Honkanen et al., 2000; Strine, Chapman, Ballluz, Moriarty, \& Mokdad, 2008).

Several studies indicated that the main predictors of SwL in old age are health, family support, religion, income, aging in place, living setting, education, social integration, sense of coherence, medication intake, quality of food and sleep (Ailshire \& Crimmins, 2011; Joia, Ruiz, \& Donalisio, 2007; von Humboldt et al., 2014). Additionally, 
several dimensions related to health and family dynamics, including relationships with adult children and economic status, have had a great effect on SwL of old people (Kim, Sugisawa, Okabayashi, Fukaya, \& Shibata, 1999). Conversely, several variables may negatively affect $S w L$ in old age, such as, the dilapidation of financial resources and autonomy, low level of education, lack of spousal relationship, low social support, comorbidities, and loss of physical and mental functioning (Burlá, Pessini, Siqueira, \& Nunes, 2014; Butler, Fujii, \& Sasaki, 2011; World Health Organization, 2015).

The literature has provided evidence for the suitability of the Satisfaction with Life Scale (SwLS) and of the quality of its psychometric properties. Previous studies have used confirmatory factor analysis and shown its validity and reliability in different cultural samples. Moreover, the SwLS has been equated with a general factor of life satisfaction (Atienza et al., 2000; Glaesmer et al., 2011; Gouveia et al., 2009; Neto, 2001; Sancho, Galiana, Gutierrez, Francisco, \& Thomas, 2014; Silva, Taveira, Marques, \& Gouveia, 2015).

Older age is a developmental period often related to loss and decline. Although these losses may be profound, a significant number of older adults cope well, by balancing personal meaning with satisfaction, wisdom and creativity. In fact, the stability-despite-loss phenomenon among older adults suggests that they report SwL and appreciation for life, despite facing challenges due to bio psychosocial restrictions, namely declines in health, cognitive impairment and loss of social roles. This opposing relationship has been reiterated in the gerontological literature as the paradox of well-being (Fernández-Ballesteros, 2007; von Humboldt, 2016; Wrosch, Scheier, Carver, \& Schulz, 2003). Moreover, some inconsistent results were found in relation to the validity and reliability of the Satisfaction with Life Scale (SwLS) in older samples (Vassar, 2008; Vassar, Ridge, $\&$ Hill, 2008); hence there is a need for more research focused on SwL with older adults.

The SwLS was validated in linguistically diverse older samples (e.g., Sancho et al., 2014; Shmotkin et al., 2006; Westerhof \& Bennett, 2005; Westerhof, Whitbourne, \& Freeman, 2011). We found no research which has validated the SwLS in a cross-national older population. Therefore, to integrate SwL in future interventions with older adults in the context of aging well, validity and reliability information about this concept is necessary. To address this question, our aim was to determine the psychometric qualities of a SwLS in cross-national older adults living in the community.

\section{Methods}

\subsection{Participants}

Potential 1400 older participants living at home, were identified and invited to provide informed consent to participate in this study. From these, 1291 older adults participated in our final sample.

Participants were mainly married women (58.2\%). Participants' level of education was high; $16.2 \%$ completed a university degree and 39.9\% completed high school. Approximately half of the participants were still professionally active (48.1\%) and reported different occupational activities, namely entrepreneurs, artists and skilled workers. All the participants lived autonomously and $50.4 \%$ of the participants had a household income above 10,000 euros per year. Additionally, $50.7 \%$ of the sample indicated to be in good health (see Table 1).

In order to facilitate the validation of the SwLS in a cross-national sample, we recruited the participants based on their availability and used the same recruitment strategy for all nationalities.

For many healthy adults, middle age is lasting longer and old age is starting later (Deeg, 2005; United Nations, 2007). There have been significant shifts in the epidemiological pattern and the profile of older people living in Portugal (Permanent Mission of Portugal to the United Nations, 2011). The respondents in our sample were aged 75 years and older, therefore fell into the older adults category, which allowed us to fully assess their perspectives of SwL in old age.

Table 1. Socio-demographic characteristics

\begin{tabular}{ccc}
\hline Characteristics & $N$ & $\%$ \\
\hline$N$ & 1291 & 100 \\
Age $(M ; S D)$ & $83.9(6.68)$ & \\
Sex & & 58.2 \\
Women & 751 & 41.8 \\
Men & 540 & \\
\hline
\end{tabular}




\begin{tabular}{|c|c|c|}
\hline \multicolumn{3}{|l|}{ Nationality } \\
\hline Angolan & 285 & 22.1 \\
\hline Brazilian & 314 & 24.3 \\
\hline English & 341 & 26.4 \\
\hline Portuguese & 351 & 27.2 \\
\hline \multicolumn{3}{|l|}{ Education } \\
\hline$<$ High school & 1082 & 83.8 \\
\hline$\geq$ High school & 209 & 16.2 \\
\hline \multicolumn{3}{|l|}{ Marital Status } \\
\hline Married or in a relationship & 725 & 56.2 \\
\hline Not married nor in a relationship & 566 & 43.8 \\
\hline \multicolumn{3}{|l|}{ Professional Status } \\
\hline Inactive & 670 & 51.9 \\
\hline Active & 621 & 48.1 \\
\hline \multicolumn{3}{|l|}{ Family Annual Income } \\
\hline$\leq 10,000 €$ & 640 & 49.6 \\
\hline$\geq 10,001 €$ & 651 & 50.4 \\
\hline \multicolumn{3}{|l|}{ Perceived Health } \\
\hline Good & 655 & 50.7 \\
\hline Poor & 636 & 49.3 \\
\hline
\end{tabular}

Note. $M=$ mean; $S D=$ standard deviation.

\subsection{Material}

This study included the following measures: (a) SwLS with good reliability $(\alpha=.78)$ (Diener et al., 1985); (b) Orientation to Life Questionnaire (OtLQ) ( $\alpha=.82$ ) (Antonovsky, 1993; von Humboldt \& Leal, 2015); (c) Positive and Negative Affect Schedule (PANAS) with a high internal consistency $(\alpha=.88$ and $\alpha=.87$, respectively) (Watson, Clark, \& Tellegen, 1988); (d) Adjustment to Aging Scale (AtAS) $(\alpha=.89)$ (von Humboldt, 2016; von Humboldt, Leal, Pimenta, \& Maroco, 2013), and (e) Socio-demographic and health status questionnaires. In addition, one measure of cognitive functioning, the Mini-Mental State Exam (MMSE) was employed.

\subsection{Procedure}

Older adults living in the community were invited to the research by means of an accompanying letter one month prior to the commencement of data collection. All participants received a document which contained relevant information on the purpose and procedures of this validation study. They were assured of privacy and confidentiality. They were informed that they could interrupt their participation from the study at any point. Questionnaires were coded, thus the identity of participants was not revealed. Participants were eligible to be included in the study if they were aged 75 years and older, able to understand and provide informed consent in relation to the study, and scored in the normal range of the MMSE (>26) (Folstein, M., Folstein, S., \& McHugh, 1975).

This research was fully approved by the William James Center for Research, from ISPA-Instituto Universitário and the Portuguese Foundation for Science and Technology (FCT).

Scores for the SwLS, PANAS, OtLQ AND AtAS were analysed using established statistical techniques (to generate sample means, standard deviations, medians and ranges) in the Statistical Packages for Social Sciences (SPSS) Version 20.0.

Validity indicates the degree to which the instrument is measuring what it is intended to measure. Construct validity is one of three main types of evidence of validity, alongside criterion validity and external validity. In 
order to analyze overall validity of the SwLS, construct-related, criterion and external validity, reliability and distributional properties were evaluated.

Construct validity indicates the extent to which a test measures the construct it purports to be measuring. We used Confirmatory Factor Analysis (CFA) to assess the construct validity of SwLS. In order to assess the structure of the scale factor, a varimax rotation method was used and principal components factor analysis was applied to scores obtained from answers given by the participants.

We also used the following statistics: chi-square $\left(X^{2} / d f\right)$, Comparative Fit Index $(C F I)$, Goodness of Fit Index (GFI) and Root Mean Square Error of Approximation (RMSEA). Convergent and discriminant validity are both subtypes of construct validity. Convergent validity is verified when measures that are theoretically expected to correlate are indeed related (AVE scores $>.450$ ). Discriminant validity indicates the extent to which it is possible to discriminate between constructs that are theoretically expected to not be related (squared correlation between factors $<$ individual factor AVE).

Criterion validity measures how well one measure predicts the outcome of another measure.

External validity indicates the extent to which the results of this study are stable and can be generalized beyond the study sample. A confirmatory factor analysis was performed in $60 \%$ of the sample, and the factor weights and correlations stability were evaluated in $40 \%$ of the sample (Maroco, 2010).

Distributional properties were evaluated through the exploration of minimum and maximum values, mean, skewness and kurtosis. Reliability indicates the degree to which the instrument consistently measures what it is intended to measure. For this purpose, we used the Cronbach's alpha.

\section{Results}

\subsection{Construct Related Validity}

\subsubsection{Confirmatory Factor Analysis}

Confirmatory Factor Analysis (CFA) was employed in the five items in the data set and provided a good fit based on the goodness-of-fit statistics: $\chi^{2} / d f=2.734, p<.001, C F I=.999, G F I=.996, R M S E A=.037, p=.800,90 \%$ confidence interval for the RMSEA $=[.014 ; .061]$.

\subsubsection{Convergent Validity}

All factors presented good AVE scores (i.e., equal or above .50), thus demonstrating the convergent related validity of the factors (see Table 2).

The acceptable AVE score was .673, thus exhibiting good strength (see Table 2).

Table 2. Satisfaction with Life Scale: convergent validity and reliability

\begin{tabular}{ccc}
\hline Satisfaction with Life Scale & AVE & Cronbach's Alpha \\
\hline Overall scale & .673 & .899 \\
\hline
\end{tabular}

\subsection{Criterion Validity}

The OtLQ and PANAS presented divergent criterion validity. SwLS total score was positively and weakly correlated with OtLQ total score $(r=.255 ; p<.001)$ and with PANAS total a $(r=.092 ; p=.001)$. No other correlations were significant or superior in absolute value to the identified correlations.

\subsection{External Validity}

Support for external validity of the SwLS measurement was obtained in $60 \%$ and $40 \%$ of the sample with a good fit: $\left(X^{2} / d f=1.764 ; C F I=.999 ; G F I=.995 ;\right.$ RMSEA $\left.=.024 ; p=.992 ; C . I .90 \%=[.000 ; .043]\right)$, hence the unconstrained measurement model does not have a significantly better fit than the model with constrained factorial weights $\left(X^{2}(4)=1.416 ; p=.841\right)$ and the stability of the SwL was considered good.

\subsection{Item Analysis}

Overall, the summary statistics indicated skewness and the kurtosis values of the five items, below three and seven, respectively. Items classification ranged between one and seven (see Table 3). 
Table 3. Satisfaction with Life Scale: values concerning minimum and maximum scores, skewness and kurtosis

\begin{tabular}{ccccc}
\hline Items & Minimum & Maximum & Skewness & Kurtosis \\
\hline 1 & 1 & 7 & .022 & -.674 \\
2 & 1 & 7 & -.244 & -1.050 \\
3 & 1 & 7 & -.057 & -.217 \\
4 & 1 & 7 & .175 & -.807 \\
5 & 1 & 7 & .032 & -.639 \\
\hline
\end{tabular}

\subsection{Reliability}

The overall scale reliability including the five items was good, with Cronbach's alpha for the SwLS being .899 (see Table 2).

\section{Discussion}

This research intended to validate a SwL measure in an old sample. SwLS delivered data with good psychometric properties in our sample of older adults. Thus, this instrument may be used to directly assess the level of SwL in older populations. Early psychometric evaluation of SwLS with older samples consisted of a relatively small convenient sample ( $n=53$ ), with an average age of 75 , with good internal consistency across items (Diener et al., 1985). Later the SwLS was assessed in samples other than English, such as Angolan, Dutch, German older adults (Sancho et al., 2014; Westerhof \& Bennett, 2005; Westerhof, Whitbourne, \& Freeman, 2011), and old-old adults also with good internal consistency scores (Shmotkin et al., 2006).

According to Diener and his colleagues (1985), future research and cultural comparisons are needed to validate SwlS in different populations. The SwLS model showed a good fit $\left(X^{2} / d f=2.734 ; C F I=.999 ; G F I=.996\right.$; $R M S E A=.037 ; p=.800 ;$ C.I. $90 \%=[.014 ; .061])$, thus corroborating previous research. Moreover, our study reiterated the SwLS as a multi-item and global evaluation of SwL with older samples, as shown across multiple age groups (Diener et al., 1985; Nieboer, Lindenberg, Boomsma, \& Van Bruggen, 2005; Poon \& Cohen-Mansfield, 2011).

These outcomes showed divergent criterion validity in the OtLQ and PANAS. Nonetheless, SwLS appears to be strongly correlated with personality measures, such as self-esteem, symptom check-list, neuroticism, emotionality, activity, sociability and impulsivity (Diener et al., 1985; Poon \& Cohen-Mansfield, 2011).

Configurational invariance was found in our results. The unconstrained measurement model does not show a better fit than the model with constrained factorial weights $\left(X^{2}(4)=1.416 ; p=.841\right)$. Despite the fact that the dimensionality of the SwLS appeared to remain the same across young and old age groups (Fujita \& Diener, 2005; Pons, Atienza, Balaguer, \& García-Merita, 2000) indicated that older participants varied significantly from younger individuals concerning the item reflecting weather conditions of life were excellent.

The reliability of SwLS was found to be very good, which corroborates the internal consistency of the SwLS found in other studies with old and very old adults (Diener et al., 1985; Sancho et al., 2014; Shmotkin et al., 2006; Westerhof \& Bennett, 2005). Contrary to these results, Vassar et al. (2008) did not report satisfactory scores for validity and reliability of SwLS with older adults.

These results should be interpreted considering the study's limitations. We used the convenience sampling method, which limits the generalizability of our findings. A larger portion of our study participants were women $(58.2 \%)$ however, this is reflective of the current demographics of older populations in developed areas. Our sample, while population-based, was $73 \%$ Caucasian and relatively well-educated. Hence our outcomes may not generalize to other populations with more diverse levels of educational and ethnicity.

This study has a cross-sectional nature. Future research is needed to discuss the stability of the SwLS. One should also investigate whether SwL is correlated to other personality measures, such as self-esteem, symptom check-list, neuroticism, emotionality, activity, sociability and impulsivity in both frail and high-functioning older populations.

The contribution of a cross-national research for validating the SwLS has a great potential in future research endeavours as the number of comparable data sets increases across diverse areas of the globe. Indeed, the inclusion of cross-cultural samples in gerontological research could benefit the understanding of the culturally-diverse concept of SwL held by older adults (Löckenhoff, 2009). 
Additionally, this study expands previous research, corroborating the relevance of SwL in older diverse populations living in the community. The nature of our community-dwelling sample intends to overcome a limitation that is usually seen in studies with older adults, since previous research is often limited to frail older individuals. In light of our findings, the authors suggest using SwLS as a measurement tool for assessing SwL among older populations, with increased autonomy, well-being and longevity.

This study corroborates the view that aging well and with $\mathrm{SwL}$ is as an interactive process that requires adaptation to different socio-cultural settings.

Validation of the SwLS in older populations is an important step in ensuring that appropriate user-driven instruments are available for assessing health-related SwL in old age, and these results will also positively stimulate additional research and practice to improve health-related SwL among older adults. Moreover, SwL has shifted to be a part of general primary care in old age, hence the use of SwLS with older adults living in the community is an important step in adequating within the needs of the healthcare system. The SwLS is an effective user-driven brief instrument which may be easily administered in using an oral interview or self-report format in interventions focused on promoting the health and well-being of older adults.

The results of this study may be used for future cross-cultural research, together with other aging well variables, such as quality of life and well-being, among older age groups with different ethnicities. Indeed, the insertion of ethnicity in future studies may contribute to deepening our understanding of cultural differences in older adults' self-reported SwL.

In conclusion, this study has provided preliminary evidence in support of the validity, reliability, and reproducibility of the SwLS in culturally-diverse older adults living in the community.

\section{Acknowledgements}

We kindly acknowledge the Portuguese Foundation for Science and Technology (FCT), for the grant [grant number SFRH/BD/44544/2008] which supported this research.

Conflict of Interest: The authors report no conflicts of interest. The authors alone are responsible for the content and writing of the paper.

Sponsor's Role: The fund approved the design and aims of the study but did not play any role in the collecting of data, interpretation of results, or preparation of this article.

\section{References}

Ailshire, J. A., \& Crimmins, E. M. (2011). Psychosocial factors associated with longevity in the United States: Age differences between the old and oldest-old in the health and retirement study. Journal of Aging Research, 530-534. https://doi.org/10.4061/2011/530534

Angelini, V., Cavapozzi, D., Corazzini, L., \& Paccagnella, O. (2011). Age, Health and Life Satisfaction Among Older Europeans. Social Indicators Research, 105(2), 293-308. https://doi.org/10.1007/s11205-011-9882-x

Antonovsky, A. (1993). The structure and properties of the sense of coherence scale. Social Science and Medicine, 36(6), 725-733. https://doi.org/10.1016/0277-9536(93)90033-Z

Atienza, F. L., Pons, D., Balaguer, I., \& García-Merita, M. (2000). Propiedades psicométricas de la Escala de Satisfacción con la Vida en adolescents [Psychometric properties of Satisfaction with Life Scale in adolescents]. Psicothema, 12, 314-319.

Brown, J., Bowling, A., \& Flynn, T. (2004). Models of quality of life: A taxonomy, overview and systematic review of the literature. In European Forum on Population Ageing Research, 2004. Sheffield: Department of Sociological Studies.

Burlá, C., Pessini, L., Siqueira, J. E., \& Nunes, R. (2014). Envelhecimento e doença de Alzheimer: Reflexões sobre autonomia e o desafio do cuidado [Aging and Alzheimer disease: Reflexions over autonomy and care challenge]. Revista Bioética, 22(1), 85-93. https://doi.org/10.1590/S1983-80422014000100010

Butler, J. P., Fujii, M., \& Sasaki, H. (2011). Balanced aging, or successful aging? Geriatrics \& Gerontology International, 11(1), 1-2. https://doi.org/10.1111/j.1447-0594.2010.00661.x

Byrne, B. M. (2001). Structural equation modelling with AMOS: Basic concepts, 280 applications and programming. London, England: LEA.

Deeg, D. J. H. (2005). The development of physical and mental health from late midlife to early old age. Dementia and Geriatric Cognitive Disorders, 19, 316-323. https://doi.org/10.4135/9781452225999.n7 
Diener, E., Emmons, R. A., Larsen, R. J., \& Griffin, S. (1985). The satisfaction with life scale. Journal of Personality Assessment, 49, 71-75. https://doi.org/10.1207/s15327752jpa4901_13

Fernandes, M. G. M., Silva, A. O., Loureiro, L. S. N., \& Medeiros, A. C. T. (2011). Indicadores e condições associadas ao envelhecimento bem-sucedido: Revisão integrativa da literatura [Indicators and conditions associated to successful aging]. Cogitare Enfermagem, 16(3), 543-548. https://doi.org/10.5380/ce.v16i3.24291

Fernández-Ballesteros, R. (2007). Gero Psychology. In European perspectives for an aging world. Washington, DC: Hogrefe \& Huber Publishers.

Folstein, M. F., Folstein, S. E., \& McHugh, P. R. (1975). Mini-mental state. A practical method for grading the cognitive state of patients for the clinician. Journal of Psychiatric Research, 12, 189-198. https://doi.org/10.1016/0022-3956(75)90026-6

Fujita, F., \& Diener, E. (2005). Life satisfaction set point: Stability and change. Journal of Personality and Social Psychology, 88, 158-164. https://doi.org/10.1037/0022-3514.88.1.158

Glaesmer, H., Grande, G., Braehler, E., \& Roth, M. (2011). The German version of the Satisfaction with Life Scale (SWLS): Psychometric properties, validity, and population-based norms. European Journal of Psychological Assessment, 27, 127-132. https://doi.org/10.1027/1015-5759/a000058

Gouveia, V. V., Milfont, T. L., Fonseca, P. N., \& Coelho, J. A. (2009). Life satisfaction in Brazil: Testing the psychometric properties of the Satisfaction With Life Scale (SWLS) in five Brazilian samples. Social Indicators Research, 90, 267-277. https://doi.org/10.1007/s11205-008-9257-0

Gwozdz, W., \& Sousa-Poza, A. (2009). Ageing, health and life satisfaction of the oldest old: An analysis for Germany. Social Indicators Research, 97(3), 397-417. https://doi.org/10.1007/s11205-009-9508-8

Joia, L. C., Ruiz, T., \& Donalisio, M. R. (2007). Condições associadas ao grau de satisfação com a vida entre a população de idosos [Conditions associated to life satisfaction among older adults]. Revista Saúde Pública, 4l(1), 131-138. https://doi.org/10.1590/s0034-89102007000100018

Kim, H. K., Sugisawa, H., Okabayashi, H., Fukaya, T., \& Shibata, H. (1999). A longitudinal study on social support and life satisfaction among Japanese elderly. Japanese Journal of Public Health, 46(7), 532-541.

Koivumaa-Honkanen, H., Honkanen, R., Viinamaki, H., Heikkila, K., Kaprio, J., \& Koskenvuo, M. (2000). Self-reported life satisfaction and 20-year mortality in healthy Finnish adults. American Journal of Epidemiology, 152, 983-991. https://doi.org/10.1093/aje/152.10.983

Litwin, H. (2005). Correlates of successful aging: Are they universal? International Journal Aging Human Development, 61, 313-333. https://doi.org/10.2190/DUGV-AQPU-PT28-B8D7

Löckenhoff, C. E., De Fruyt, F., Terracciano, A., McCrae, R. R., De Bolle, M., \& Costa, P. T. Jr. (2009). Perceptions of aging across 26 cultures and their culture-level associates. Psychology and Aging, 24(4), 941-954. https://doi.org/10.1037/a0016901

Maroco, J. (2010). Análise de equações estruturais [Structural equations analysis]. Pero Pinheiro: Report Number.

Moody, H. R. (2003). Conscious aging: A strategy for positive change in later life. In J. L. Ronch, \& J. A. Goldfield (Eds.), Mental wellness in aging: Strength-based approaches (pp. 139-160). Winnipeg: Health Professions Press.

Neto, F. (2001). Satisfaction with life among adolescents from immigrant families in Portugal. Journal of Youth and Adolescence, 30, 53-67. https://doi.org/10.1023/A:1005272805052

Nieboer, A., Lindenberg, S., Boomsma, A., \& Van Bruggen, A. C. (2005). Dimensions of well-being and their measurement: The SPF-IL Scale. Social Indicators Research, 73, 313-353. https://doi.org/10.1007/s11205-004-0988-2

Pavot, W., \& Diener, E. (2004). The subjective evaluation of well-being in adulthood: Findings and implications. Ageing International, 29(2), 113-135. https://doi.org/10.1007/s12126-004-1013-4

Permanent Mission of Portugal to the United Nations. (2011). Portugal's views on the situation of the rights of older persons. Retrieved from http://www.ohchr.org/Documents/Issues/OlderPersons/Submissions/Portugal.pdf 
Pons, D., Atienza, F. L., Balaguer, I., \& García-Merita, M. L. (2000). Satisfaction with Life Scale: Analysis of factorial invariance for adolescents and elderly persons. Perceptual and Motor Skills, 91, 62-68. https://doi.org/10.2466/pms.2000.91.1.62

Poon, L. W., \& Cohen-Mansfield, J. (2011). Understanding well-being in the oldest old. New York: Cambridge University Press. https://doi.org/10.1017/CBO9780511920974

Sancho, P., Galiana, L., Gutierrez, M., Francisco, E. H., \& Tomas, J. M. (2014). Validating the Portuguese version of the Satisfaction with Life Scale in an elderly sample. Social Indicators Research, 115, 457-466. https://doi.org/10.1007/s11205-012-9994-y

Shmotkin, D., Berkovich, M., \& Cohen, K. (2006). Combining happiness and suffering in a retrospective view of anchor periods in life: A differential approach to subjective well-being. Social Indicators Research, 77(1), 139-169. https://doi.org/10.1007/s11205-005-5556-x

Silva, A., D., Taveira, M. C., Marques, C., \& Gouveia, V. V. (2015). Satisfaction with Life Scale among adolescents and young adults in Portugal: Extending evidence of construct validity. Social Indicators Research, 120(1), 309-318. https://doi.org/10.1007/s11205-014-0587-9

Sposito, G., D’Elboux, M. J., Neri, A. L., \& Guariento, M. E. (2013). A satisfação com 20 [Satisfaction with life and functionality in elderly patients at a clinic for geriatrics]. Ciência \& Saúde Coletiva, 18(12), 3475-3482. https://doi.org/10.1590/S1413-81232013001200004

Strine, T. W., Chapman, E. D. P., Ballluz, E. L. S., Moriarty, D. G., \& Mokdad, E. A. H. (2008). The associations between life satisfaction, chronic illness, and health behaviors among U.S. community-dwelling adults. Journal of Community Health, 33, 40-50. https://doi.org/10.1007/s10900-007-9066-4

United Nations. (2007). World Population Aging 2007. Department of Economic and Social Affairs: Population Division.

Vassar, M. (2008). A note on the score reliability for the Satisfaction with Life Scale: An RG study. Social Indicators Research, 86, 47-57. https://doi.org/10.1007/s11205-007-9113-7

Vassar, M., Ridge, J. W., \& Hill, A. D. (2008). Inducing score reliability from previous reports: An examinations of life satisfaction studies. Social Indicators Research, 87(1), 27-45. https://doi.org/10.1007/s11205-007-9157-8

Von Humboldt, S. (2016). Conceptual and methodological issues on the adjustment to aging: Perspectives on aging well. New York, NY: Springer. https://doi.org/10.1007/978-94-017-7576-2

Von Humboldt, S., \& Leal, I. (2015). The Orientation to Life Questionnaire: Validation of a measure to assess older adults' sense of coherence. Educational Gerontology, 41(6), 451-465. https://doi.org/10.1080/03601277.2014.983373

Von Humboldt, S., Leal, I., \& Pimenta, F. (2014). Living well in later life: The influence of sense of coherence, and socio-demographic, lifestyle and health-related factors on older adults' satisfaction with life. Applied Research in Quality of Life, 9, 631-642. https://doi.org/10.1007/s11482-013-9262-6

Von Humboldt, S., Leal, I., Pimenta, F., \& Maroco, J. (2013). Assessing adjustment to aging: A validation study for the Adjustment to Aging Scale (AtAS). Social Indicators Research [Epub ahead of print].

Watson, D., Clark, L. A., \& Tellegen, A. (1988). Development and validation of brief measures of positive and of positive and negative affect: The PANAS scales. Journal of Personality and Social Psychology, 54(6), 1063-1070. https://doi.org/10.1037/0022-3514.54.6.1063

Westerhof, G. J., \& Barrett, A. E. (2005). Age identity and subjective well-being: A comparison of the United States and Germany. The Journals of Gerontology Series B: Psychological Sciences and Social Sciences, 60B, 129-136. https://doi.org/10.1093/geronb/60.3.S129

Westerhof, G. J., Whitbourne, S. K., \& Freeman, G. P. (2011). The aging self in a cultural context: The relation of conceptions of aging to identity processes and self-esteem in the United States and the Netherlands. Journal of Gerontology Series B: Psychological Sciences and Social Sciences, 67B(1), 52-60. https://doi.org/10.1093/geronb/gbr075

World Health Organization. (2015). Worls Health Statistics 2015. Geneva: The Author. 
Wrosch, C., Scheier, M. F., Carver, S. C., \& Schulz, R. (2003). The importance of goal disengagement in adaptive self-regulation: When giving up is beneficial. Self and Identity, 2, 1-20. https://doi.org/10.1080/15298860309021

\section{Copyrights}

Copyright for this article is retained by the author(s), with first publication rights granted to the journal.

This is an open-access article distributed under the terms and conditions of the Creative Commons Attribution license (http://creativecommons.org/licenses/by/4.0/). 